\title{
Small Stakes Give You the Blues: The Skeptical Costs of Pragmatic Encroachment
}

\author{
Clayton Littlejohn \\ King's College London \\ Department of Philosophy \\ Strand Campus \\ London, England \\ United Kingdom of Great Britain and Northern Ireland \\ cmlittlejohn@gmail.com
}

Article info

CDD: 144.3

Received: 03.09.2017; Accepted: 09.10.2017

DOI: http://dx.doi.org/10.1590/0100-6045.2017.V40N4.CL

Keywords:

Knowledge

Pragmatic Encroachment

\begin{abstract}
According to the fallibilist, it is possible for us to know things when our evidence doesn't entail that our beliefs are correct. Even if there is some chance that we're mistaken about $p$, we might still know that $p$ is true. Fallibilists will tell you that an important virtue of their view is that infallibilism leads to skepticism. In this paper, we'll see that fallibilist impurism has considerable skeptical consequences of its own. We've missed this because we've focused our attention on the high-stakes cases that they discuss in trying to motivate their impurism about knowledge. We'll see this once we think about the fallibilist impurist's treatment of low-stakes cases. [...] when error would be especially disastrous, few possibilities are properly ignored (Lewis 1996: 556, n. 12).
\end{abstract}

If forced to choose between fallibilism and skepticism, many of us would plump for fallibilism. Many of us suspect that Lewis might have been right that fallibilism is the less intrusive madness. If it is, it is only because the fallibilist offers us a coherent alternative to skepticism. Does it?

Some version of it might, but I fear that a seemingly promising form of it has skeptical consequences that hadn't been noticed. In this brief paper, I shall argue that fallibilist impurism has unacceptable skeptical consequences.

Our fallibilist thinks that it is possible for a thinker to know $p$ even if the thinker's total evidence does not entail $p$. On this view, a thinker might know $p$

Manuscrito - Rev. Int. Fil. Campinas, v. 40, n. 4, pp. 31-38, out.dez. 2017. 
but still be rationally compelled to assign $\sim p$ positive probability. The fallibilist thinks that a virtue of their view is that they dodge the skeptical problems that are thought to arise for the infallibilist. As they see things, we rarely if ever have entailing evidence that supports our beliefs about the external world, so if the infallibilist claims that such evidence is a necessary condition for knowledge, our fallibilist thinks that this infallibilist view quickly leads to skepticism. ${ }^{1}$

Our fallibilist is also an impurist. She thinks that the value of knowledge derives, in part, from what knowledge gives us. According to Fantl and McGrath, knowledge gives us reasons. When we have a reason (in their sense), it can play a role in justifying our actions and attitudes:

Safe Reasons: If $p$ is a reason you have to $\phi, p$

is warranted enough to justify you in $\phi$-ing, for any $\phi(2009$ : 77).

Reasons are thus a valuable commodity because having them (in this sense) can have a direct bearing on what's rational to do. To have a reason, they say, we only need to know that the relevant proposition is true:

KR: If you know that $p, p$ is warranted enough to be a reason you have to $\phi$, for any $\phi$ (2009: 69). ${ }^{2}$

Thus, on their picture, knowledge gives us a valued commodity. To know is, inter alia, to have the kind of warrant we need to properly treat things as

\footnotetext{
${ }^{1}$ For arguments that the skeptical costs of infallibilism have been overstated, see Dutant (2016) and Williamson (2000). On Williamson's view, the possession of entailing evidence for a proposition would be a trivial consequence of coming to know it. This is, given some standard assumptions about evidential support, a trivial consequence of his thesis that our evidence just is our knowledge.

${ }^{2}$ For a defense of KR, see Hawthorne (2004). For a critical discussion of the thesis, see Anderson (2015), Brown (2008), and Roeber (forthcoming). The argument in this paper is not designed to show that $\mathrm{KR}$ is false, only that impurism is not an attractive position for people put off by skepticism.
}

Manuscrito - Rev. Int. Fil. Campinas, v. 40, n. 4, pp. 31-38, out.-de\%. 2017. 
reasons. When we can properly treat things as reasons, this can simplify rational deliberation considerably:

The picture of having reasons ... is a 'ledgerkeeping' one ... When a proposition is a reason you have to $\phi \ldots$ it gets put in the ledger with the countervailing reasons and weighed against them. But the probabilities of these reasons don't get recorded alongside (2009: 79).

As they see things, we are sometimes right to reason by weighing the pros and cons without any concern for the probabilities on our evidence that these considerations are true.

Fantl and McGrath argue that if we accept this much (i.e., fallibilism, Safe Reasons, and KR) we should also accept impurism. According to the impurist, the adequacy of a thinker's evidence or grounds depends upon the practical significance of being mistaken about some target proposition. As the stakes increase (i.e., the subject stands to lose more by being mistaken in believing the target proposition), evidence that might have been adequate to justify beliefs in low-stakes situations ceases to be adequate to justify the thinker's belief and so greater evidential support is required for justification and knowledge.

Consider a simple example. Agnes asks a woman seated on the bench if this train is going to Boston. She assures Agnes that it is and Agnes comes to know that this train is going to Boston. If Agnes wants to go to Boston because it seems a pleasant place to spend the afternoon, it seems that this knowledge gives her a reason to board. If she boards, her decision to board would presumably be justified. Suppose, however, that Agatha also wanted to catch a train to Boston because she needs to get there as quickly as possible to try to make it to some terribly important meeting. (Is it a job interview? Does she need to find a doctor with an antidote? Is she going to try to assassinate the Prime Minister? She doesn't say.) She overhears the woman tell Agnes that this is a train to Boston. She knows that if she boards and it is one of the many trains that would not take her to Boston that this would be a disaster. (She won't get the job? She won't live through the night? The Prime Minister will live through the night? We don't know.) Agatha can double check or board 
straight away. It would cost her something to check, but the cost of checking isn't as great as the cost of getting on the wrong train.

Fantl and McGrath think that it would be irrational for Agatha to board without checking. Given her evidence, there is still some chance that the train won't take her to Boston. If it didn't, it would be a disaster. That might seem right, but then it seems something strange is going on. If Agatha knew that the train was going to Boston, it wouldn't be rational to pay the price to check. Since Agnes and Agatha have the same grounds for their belief, how could it be that it's rational for one but not the other to board without checking? Surely if Agatha knew that the train was going to Boston, it would be irrational for her to pay the cost to check. Isn't that what Safe Reasons and KR implies?

It is. If Agatha knew that the train was going to Boston, it would be irrational, Fantl and McGrath say, for Agatha to check instead of boarding straight away. How, then, could they say that Agatha is rationally required to check and Agnes is rationally permitted to board without checking?

They propose that there is a difference in what these two agents can know. They have the same grounds for their belief (i.e., the testimony of the woman on the bench) but this gives Agnes knowledge-level justification and does not do the same for Agatha. As they see things, knowledge doesn't require that your evidence raises the probability of the truth of your beliefs to 1, only that it makes them probable enough to properly serve as a basis for your decisions. In Agnes' case, a proposition needn't be highly probable to properly figure as a premise in her deliberation because the costs of being wrong for Agnes are low. In Agatha's case, however, a proposition must be highly probable to figure as a premise in her deliberation because the costs of being wrong are quite high.

The lesson that Fantl and McGrath draw from these kinds of cases is this. Whether any agent knows or not depends, in part, upon whether her belief could be properly relied on in deciding what to do. When we compare someone who fallibly knows $p$ on some basis to someone who believes $p$ on the same basis in a high stakes situation, that basis might not provide this subject with knowledge-level justification for her belief. In the high stakes case, then, the subject's belief would not be knowledge even if it were true because the grounds that constitute belief's rational basis would not warrant reasoning from that belief or putting that belief in the ledger.

As they see things, we cannot square fallibilism with this picture of the value of knowledge without allowing for pragmatic encroachment. To know $p$, it is fine if there is some chance that $p$ is false, but it had better be that the chance 
that $p$ is false doesn't stand in the way of acting on $p$. Part of their methodology is to rely on judgments about the high stakes case to motivate their position. In such cases, knowledge is difficult to attain. In low stakes cases, however, I think they'd want to say that knowledge is as easy to attain as we initially took it to be.

I fear that their view faces much more skeptical pressure than they appreciate. To see why, let's consider the lowest stake cases. Agnes doesn't particularly like to drink, but she'll have a drink with coworkers now and then. She has the slightest preference for a glass of wine to nothing and the slightest preference for a well-made martini to a glass of wine. She is indifferent when it comes to a poorly made martini and a glass of wine:

\begin{tabular}{|l|c|c|}
\hline & Good Bartender & Bad Bartender \\
\hline Wine & +.000000001 & +.000000001 \\
\hline Martini & +.000000002 & +.000000001 \\
\hline
\end{tabular}

According to Fantl and McGrath, infallibilism leads to skepticism. If Agatha couldn't know that the bartender was bad unless her evidence entailed this, Agatha couldn't know the bartender was bad. So, if Agatha knows the bartender is bad, they'll say that she still has to assign positive probability to Good Bartender. If Agatha assigns positive probability to Good and Bad Bartender, Martini weakly dominates Wine. If Martini weakly dominates Wine, Agatha cannot use as a premise in her reasoning the fact that the bartender is bad. If she could use this premise in her reasoning, she could be rationally indifferent between Wine and Martini. Since Wine is weakly dominated, it would not be proper for her to treat the fact that the bar tender is bad, so, according to KR, Agatha cannot know this. ${ }^{3}$

There is no case with lower stakes than this. The lesson we should take from this is that fallibilist impurism doesn't just deny us knowledge in highstakes situations. It also denies us knowledge in the absurdly low-stakes situations like the one just described. It says that however low the stakes get, it

${ }^{3}$ See Anderson and Hawthorne (forthcoming) for a helpful discussion of the relationship between the epistemic position that we must have to properly treat something as a reason for action and the stakes of error. They observe that worries about knowing in high-stakes cases and having warrant to treat things as reasons for action come apart in ways that fallibilist impurists hadn't anticipated.

Manuscrito - Rev. Int. Fil. Campinas, v. 40, n. 4, pp. 31-38, out.-der. 2017. 
isn't possible for any thinker to acquire sufficient evidence to know $p$ when one of her choices involves an option that is (a) weakly dominated and (b) at least as good as the alternatives if $p$ is true.

How common are these cases? They might be very common. Some of us don't like to make mistakes but don't get all that excited about having true beliefs when it comes to matters that aren't connected to issues that interest us or have any obvious connection to our practical concerns. I can't speak for you, but it seems to me that there are large sets of propositions where (a) I'd regret believing them falsely but (b) couldn't really care about whether I believe them correctly or just didn't believe anything at all. Just the other day, for example, Charles told me that state beverage of Delaware is milk. I hadn't asked. I've never cared to know. He just told me that this and thus forced to consider whether it was true. His say so seems like it might be enough to justify believing any number of dull propositions, this one included. He then observed that if the state beverage is milk, it is also true that either the state beverage is milk or two plus two is five.

Let's consider the options, states, and the value of the outcomes of believing this disjunction, suspending judgment, or believing the disjunction to be false:

\begin{tabular}{|l|c|c|}
\hline & Disjunction is true & Disjunction is false \\
\hline $\begin{array}{l}\text { Believe } \\
\text { Disjunction }\end{array}$ & 0 & -.0000000000000000001 \\
\hline Suspend & 0 & 0 \\
\hline $\begin{array}{l}\text { Believe } \\
\text { Disjunction is } \\
\text { False }\end{array}$ & -.0000000000000000001 & 0 \\
\hline
\end{tabular}

If I could know on the basis of Charles' testimony that the state beverage is milk, I'd have as a reason (in Fantl and McGrath's sense) this fact. If I had this fact as one of my reasons, it would justify believing the disjunction and I could treat this reason as a reason for Believe Disjunction. However, this option is weakly dominated. If I had this fact among my reasons, it would be acceptable to 'choose' this option, but as it is not acceptable to go for a weakly dominated option, I must not have this fact among my reasons. Thus, according to KR, I couldn't know that the state beverage of Delaware is milk.

The option wouldn't be weakly dominated if either (a) some good would come of Believe Disjunction or (b) my evidence warranted me in giving no 
credence to the falsity of the disjunction. Our fallibilist thinks that (b) could never be satisfied, so no change in my evidential situation would warrant me in treating the first thing Charles told me as a truth in settling the question about whether his disjunction is true. It would appear that if no good could come of believing that milk is the state beverage, I would never know if Charles spoke the truth. I'm okay with not knowing if Charles spoke the truth here, but the general skeptical result would worry me since I think that I could, in principle, learn all kinds of boring things from the testimony of my friends.

If these absurdly low-stakes cases prevent us from knowing things like this, the skeptical consequences of fallibilist impurism are not insignificant. They might be less bad than, say, the skeptical consequences of infallibilism, but they might be bad enough to warrant saying that the impurism our fallibilists accept isn't helpful for fending off skeptical challenges. To my mind, these are intolerable skeptical results. A run of bad martinis is all we need to know that a bartender is bad. Complete indifference to whether a martini is good or bad isn't the key to resisting skeptical pressure. You can use Google to learn about Delaware if Charles isn't around. On the assumption that the fallibilist impurists don't want to reject parts of standard decision theory, they'll have to embrace skepticism or reject something from the package of views that motivates impurism. If they deny Safe Reasons or KR, it doesn't look as if their cases could provide any motivation for their view about knowledge. They are free to try to argue against the standard norms from decision theory, but if I were a betting man, I'd bet on standard decision theory.

\section{References}

ANDERSON, C. "On the Intimate Relationship of Knowledge and Action". Episteme 12: 343-53, 2015.

\& Hawthorne, J. (forthcoming). "Knowledge, Practical Adequacy, and Stakes". In J. Hawthorne, \& T. Gendler (Eds.), Oxford Studies in Epistemology (Vol. 6). Oxford University Press.

Brown, J. "Subject-Sensitive Invariantism and the Knowledge Norm for Practical Reasoning". Nous 42: 167-89, 2008.

DutANT, J. "How to be an Infallibilist". Philosophical Issues 26: 148-71, 2016. 
FANTL, J., \& MCGRATH, M. Knowledge in an Uncertain World. Oxford University Press, 2009.

Hawthorne, J. Knowledge and Lotteries. Oxford University Press, 2004.

LEWIS, D. "Elusive Knowledge". Australasian Journal of Philosophy 74: 549-67, 1996.

Roeber, B. (forthcoming). "The Pragmatic Encroachment Debate". Nous.

Williamson, T. Knowledge and its Limits. Oxford: Oxford University Press, 2000. 